\title{
PCR Development for the Diagnosis of Dermatophytes in Equines
}

\author{
Méndez-RS ${ }^{1}$, Cervantes-ORA ${ }^{1 \S}$, Hernández-HF$^{2}$ and Martínez-GD 3 \\ ${ }^{1}$ Laboratory Mycology, Microbiology and Immunology Department, FMZ-UNAM, Mexico; ${ }^{2}$ Laboratory Mycology, \\ Microbiology Department, FM-UNAM, Mexico; ${ }^{3}$ Laboratory Microbiology Agricultural, UAM-Xochimilco, Mexico \\ ${ }^{\S}$ Deceased \\ *Corresponding author: sof.mdz.riv@gmail.com
}

\begin{abstract}
\begin{tabular}{llll}
\hline Article History: 20-014 Received: 15-Jan-20 & Revised: 15-Nov-20 & Accepted: 23-Nov-20
\end{tabular}
\section{ABSTRACT}

Development and standardize of PCR for diagnose of most common equine dermatophytes was carried out. We used one reference strain and four isolates characterized by routinely methods from clinical samples. Sabouraud broth was used to obtain the fungal mass by long 8 days incubation. Once the mass was dried, it was pulverized with liquid nitrogen in a mortar and deposited in tubes to obtained DNA by phenolic extraction. NCBI GenBank data were used for the primer design, the sequences were aligned manually and once the initiators were selected, they were placed in the DNAMAN program, in order to differentiate the five species involved. We diagnosed successfully common dermatophytes in Equidae by standardized PCR test. A total of 50 samples were used for the challenge test, 22 have been declared positive by conventional diagnostic methods, and the remaining samples were selected randomly the obtained results were similar compared with conventional test. $M$. canis primers were highly sensitive. For the others species we need more samples to corroborate the usefulness of the test.
\end{abstract}

Key words: Equines, Dermatophytosis, Dermatophytes, Molecular diagnosis, PCR.

(C2020 IJVS - All Rights Reserved

\section{INTRODUCTION}

Dermatophytosis is an infection caused by a group of keratinophilic fungi called dermatophytes, which affect keratinized tissues such as skin, hair, hoofbeats, horns and feathers, among other cutaneous adnexa of animals and humans (ST-Germain et al. 2011; Acha et al. 2001). Previously, this group of keratinophilic fungi consisted only of three genera, Trichophyton, Microsporum and Epidermophyton (Garg et al. 2009); however, a new taxonomic classification has been proposed which includes the following seven genera: Artrhoderma, Trichophyton, Microsporum, Nannizzia, Lophophyton, Paraphyton and Epidermophyton (De Hoog et al. 2016; Hamad et al. 2019; Kandemir et al. 2020).

These fungi have a worldwide distribution (Begum et al. 2020) In animals, they only produce tinea, while in humans they can cause onychomycosis, as well as different types of tinea, depending on the anatomic site of the lesion (Bonifaz et al. 2010). In equines, the most commonly isolated species correspond to Trichophyton equinum, Trichophyton verrucosum, Trichophyton mentagrophytes, Nannizzia gypsea (Microsporum gypseum) and Microsporum canis (Salem et al. 2018; Grob et al. 2018; Abd-Elmegeed et al. 2020; Dukik et al. 2020).
Since equine dermatophytoses show variable clinical conditions, they can be confused with other diseases. The differential diagnoses are dermatophilosis, bacterial folliculitis, scabies, allergic reaction to insect bites and sarcoidosis (Pascoe et al. 2009; Silva et al. 2018). However, in order to have an accurate diagnosis, it is necessary to carry out the isolation of the fungus through cultures and microscopic identification. For the mycological culture, it is necessary to obtain a sample of the infected tissue by scraping or plucking the affected area, but first it is important to clean it in order to reduce the presence of environmental contaminating fungi (Parmar et al. 2018; Paryuni et al. 2020). The main disadvantage of conventional diagnosis is the growth time of dermatophytes. In addition, it is necessary to consider the presence of environmental fungi in the sample, which are also going to develop in the culture medium at a faster rate than dermatophytes; so, it is a challenge to perform the isolation and characterization of dermatophyte fungi (Weitzman et al. 1995; St-Germain et al. 2011).

With the advent of molecular biology, different diagnostic methods have been implemented within microbiology. However, the use of these methodologies has been slow in the case of medical mycology, especially for dermatophytosis, due to their genomic complexity,

Cite This Article as: Méndez RS, Cervantes ORA, Hernández HF and Martínez GD, 2021. PCR development for the diagnosis of dermatophytes in equines. International Journal of Veterinary Science 10(2): 124-128. https://doi.org/10.47278/journal.ijvs/2020.028 
in addition to being infections that do not compromise the integrity or life of the individual (Cafarchia et al. 2013c). The main test used in human and veterinary medicine is the polymerase chain reaction (PCR). In veterinary medicine, there are some studies that have been carried out by different authors in order to diagnose this infection in horses (Chung et al. 2010; Cafarchia et al. 2013a; ElYazeed et. al. 2013) and canine and feline (Cafarchia et al. 2013b).

The aim of this study was to develop and standardize a PCR to diagnose most common dermatophytes involved in equine dermatophytosis (Nannizzia gypsea, Microsporum canis, Trichophyton verrucosum, Trichophyton mentagrophytes and Trichophyton equinum). The primers were designed specifically for each species using the sequence of region ITS 1 and ITS 2 y the gene TEF- $1 \alpha$, reported in the GenBank NCBI. In a previous work, we collected 120 samples of hair and scales and 26 samples had a positive culture that depicted the $21.6 \%$ of all samples. The species isolated were Trichophyton mentagrophytes, Trichophyton equinum, Trichophyton verrucosum, Microsporum canis and Microsporum gypseum. We use a reference strain of T. equinum obtained from CBS- Knaw Fungal Biodiversity Center, and Institute of the Royal Netherlands Academy of Arts and Sciences with an identification number CBS 292.81. We use the previous isolates for the primers test.

\section{MATERIALS AND METHODS}

\section{Isolates and Reference Strain}

We used the Trichophyton equinum (CBS 292.81) reference strain and four isolates obtained from clinical samples. The isolates corresponded to Trichophyton verrucosum, Trichophyton mentagrophytes, Microsporum canis, and Microsporum gypseum (N. gypsea).

\section{Culture for DNA Extraction}

For the culture, we used $50 \mathrm{ml}$ of Sabouraud broth $(5 \mathrm{~g}$ of meat peptone, $5 \mathrm{~g}$ of casein peptone and $20 \mathrm{~g}$ of dextrose, BD Bioxon (®) sterilized at $121^{\circ} \mathrm{C}, 15$ pounds for $15 \mathrm{~min}$. The five strains were previously cultured in Sabouraud dextrose agar dishes (SDA Bioxon $\left.{ }^{\circledR}\right)$ for 10 days, except Trichophyton verrucosum, which was cultured for 4 weeks. Next, the cultures were transferred to broth flasks and incubated shaking at $115 \mathrm{rpm}$ at $29^{\circ} \mathrm{C}$ for 10 days. In order to obtain the fungal mass, the broth was filtered using sterile filter paper. Once the filtration was finished, two washes were made with sterile distilled water and then dried between sheets of sterile filter paper (Mendoza 2002).

Once the fungal mass was dried, it was pulverized with liquid nitrogen in a mortar and deposited in $1.5 \mathrm{~mL}$ tubes with $500 \mu \mathrm{L}$ of lysis buffer (Tris HCL $50 \mathrm{mM} \mathrm{pH} \mathrm{7.2,} \mathrm{EDTA}$ $50 \mathrm{mM}$, SDS $3 \%$, mercaptoethanol $1 \%$ ) and $10 \mu \mathrm{l}$ of $\mathrm{K}$ proteinase, then were mixed and incubated at $56^{\circ} \mathrm{C}$ for one hour. Next, $500 \mu$ l of phenol: chloroform: isoamyl alcohol were added and centrifuged at $14,000 \mathrm{rpm}$ for $15 \mathrm{~min}$ at $4^{\circ} \mathrm{C}$. The supernatant was transferred to a new $1.5 \mathrm{~mL}$ tube with a 0.1 volume of $3 \mathrm{M}$ sodium acetate and $600 \mu \mathrm{l}$ of $100 \%$ ethanol; this mixture was centrifuged at 14,000rpm for 15 min at $4{ }^{\circ} \mathrm{C}$. The ethanol was decanted, while the precipitate was resuspended in $400 \mu \mathrm{L}$ of Tris-EDTA solution and $2 \mu \mathrm{L}$ of RNAse were added; then, this was incubated at $37^{\circ} \mathrm{C}$ for 60 minutes.

Finally, $1 \mathrm{~mL}$ of $70 \%$ ethanol was added and centrifuged at $14,000 \mathrm{rpm}$ for $1 \mathrm{~min}$ at $4^{\circ} \mathrm{C}$. The ethanol was decanted and the DNA was allowed to dry; next, it was resuspended in $30 \mu \mathrm{L}$ of injectable water and stored at $20^{\circ} \mathrm{C}$. DNA quantification was performed in a biophotometer (Eppendorf®, model: D-5000-3000) and a total of 50ng of DNA were used for the PCR (Mendoza 2002).

\section{Primer Design}

NCBI GenBank data were used for the primer design, particularly the sequences reported from the ITS region and the TEF1- $\alpha$ gene for the five dermatophyte species. The sequences were aligned manually and once the initiators were selected, they were placed in the DNAMAN program, in order to differentiate the five species involved. The primers used for the species T. equinum, $T$. verrucosum, $M$. canis and $M$. gypseum, corresponded to the ITS region 1 and 2. The TEF1- $\alpha$ gene was used for T. mentagrophytes (Table 1). The primers were requested and synthesized by Uniparts (Integrated DNA Technologies IDT).

\section{PCR}

For the PCR reaction, $50 \mu \mathrm{L}$ were utilized. The reagents used were $0.5 \mu \mathrm{L}$ of dNTP's at a concentration of $100 \mathrm{mM}, 5 \mu \mathrm{L}$ of $10 \mathrm{X}$ Buffer, $1.5 \mu \mathrm{L}$ of magnesium chloride, $0.5 \mu \mathrm{L}$ of oligo forward and $0.5 \mu \mathrm{L}$ of oligo reverse both at a concentration of $10 \mathrm{mM}, 0.5 \mu \mathrm{L}$ of taq polymerase (BioTechMol ${ }^{\circledR}$ ) and $2 \mu \mathrm{L}$ of genomic DNA solution $(50 \mathrm{ng} / \mu \mathrm{L})$. PCR reactions were carried out in a thermal cycler (brand: Techne®, model TC-412) under the following conditions by Refai et al. (2013): an initial denaturation at $94^{\circ} \mathrm{C}$ for 4 minutes followed by 30 cycles of which, each cycle consisted of a denaturation at $94^{\circ} \mathrm{C}$ for 30 seconds. The alignment temperature was different for each species: T. equinum $\left(55^{\circ} \mathrm{C}\right), M$. gypseum $\left(56^{\circ} \mathrm{C}\right), M$. canis $\left(58^{\circ} \mathrm{C}\right)$, T. mentagrophytes $\left(60^{\circ} \mathrm{C}\right)$ and $T$. verrucosum $\left(62^{\circ} \mathrm{C}\right)$. Then an extension was applied at $72^{\circ} \mathrm{C}$ for one minute and finally, a final extension was carried out at $72^{\circ} \mathrm{C}$ for 4 minutes (Refai et al. 2013; Psifidi et al. 2015).

The PCR product was observed on a $1.5 \%$ agarose gel stained with ethidium bromide $(5 \mathrm{mg} / \mathrm{ml})$ in a TAE $1 \mathrm{X}$ buffer at 93 amperes for 50 minutes, using a 100bp molecular weight marker (Invitrogene) ready to use. Subsequently, the amplified product was documented.

\section{Test Challenge}

In a previous work we collected 120 samples of hair and scales and 26 samples had a positive culture that depicted the $21.6 \%$ of all samples. The species isolated were: Trichophyton mentagrophytes, Trichophyton equinum, Trichophyton verrucosum, Microsporum canis, Nannizzia gypsea. We required a reference strain of $T$. equinum obtained from CBS- Knaw Fungal Biodiversity Center, and Institute of the Royal Netherlands Academy of Arts and Sciences with an identification number CBS 292.81. A total of 50 samples were used for the challenge test, 22 have been positive by conventional diagnostic and the remaining samples were selected randomly. 
Int J Vet Sci, 2021, 10(2): 124-128.

Table 1: Oligonucleotides used during the experiment; species-specific

\begin{tabular}{|c|c|c|c|}
\hline Fungal Species & ID initiator & Sequence & References \\
\hline \multirow[t]{2}{*}{ Trichophyton equinum } & TequITS-442F & 5' GCGAGCCTCTCTTTATAGC 3' & Summerbell et al. (1999) \\
\hline & TequITS-442R & 5' AAACAGATTTTGAGGCCAG 3' & Pchelin et al. (2016) \\
\hline \multirow[t]{2}{*}{ Trichophyton verrucosum } & TverITS-426F & 5' CTTCGGGGGCTTTAGCTGG 3' & Gräser et al. (1999) \\
\hline & TverITS-426R & 5' CTCAGAGAGATTTGGGGGAAGG 3' & \\
\hline \multirow[t]{2}{*}{ Trichophyton mentagrophytes } & TmenTef1-338F & 5' CTTTTTTTGTTGCTTGGTGGG 3' & Mirhendi et al. (2015) \\
\hline & TmenTef1-338R & 5' TGGAGGGGAAAGGTAAAGAGAA 3' & \\
\hline \multirow[t]{2}{*}{ Microsporum canis } & McanITS-297F & 5' TCGCCGGAGGATTACTCT 3' & Gräser et al. (1999) \\
\hline & McanITS-297R & 5' AAGCGGTGGGTGGTTACT 3' & Rakeman et al. (2005) \\
\hline \multirow[t]{2}{*}{ Microsporum. Gypseum } & MgypITS-373F & 5' ATACTGTTCCGTCTGAGCG 3' & Gräser et al. (1999) \\
\hline & MgypITS-373R & 5' ATCTCTGACGGAAACTGAGC 3' & Kong et al. (2008) \\
\hline
\end{tabular}

\section{RESULTS AND DISCUSSION}

A total of 120 samples of hair and scales were collected, where 22 were positive to isolation. Of the 120 samples collected, 50 of them underwent the PCR test; 22 positive samples were taken and the remaining 28 were selected randomly, having a $44 \%(22 / 50)$ of positive cultures. Isolated species were morphologically identified as Trichophyton mentagrophytes, Trichophyton equinum, Trichophyton verrucosum, Microsporum canis, Microsporum gypseum and Microsporum nanum. Double isolates of T. equinum and M. gypseum were carried out in four samples as show in the graph of Fig. 1. The isolates were preserved in sterile distilled water and on oat agar. After that the isolates was cultures for the DNA extraction. Then the 22 samples have been positive were used for the challenge test.

The primers were tested with the strains that would be used as reference to corroborate their specificity. M. canis had a weight close to $300 \mathrm{bp}$, whereas the approximate weights of M. gypseum and T. mentagrophytes were $373 \mathrm{bp}$ and $331 \mathrm{bp}$, respectively. Although these strains were in a close position, it was clear that they could not be confused with each other, which was useful when the test was performed on the actual samples. T. equinum was the strain with the highest weight band with $442 \mathrm{bp}$, while $T$. verrucosum was slightly less heavy with $426 \mathrm{bp}$ compared to $T$. equinum. Apparently, these strains could cause confusion at the time of performing the PCR; however, it was possible to differentiate them since each initiator had a different alignment temperature (Fig. 2). The species that had several complications in the amplification was, although all samples have the same amount of DNA, it is the species that shows a small amount of amplified compared to the other species.

In Table 2, we can see that the PCR had a specificity of $82.1 \%$ compared to the culture, the specificity represents the truly negative cases, on the other hand it also shows the sensitivity that the PCR had, which is $78.9 \%$ so it is considered within a low range because the sensitivity shows the true positives. So now we must test the PCR with the rest of the samples to corroborate those results Since in this study only the specificity and sensitivity of the primers with pure cultures were tested, then they will be tested with DNA extracted from hair samples and scales (Fig. 3). The species that had several complications in the amplification was Trichophyton mentagrophytes.

Conventional mycological diagnosis remains the most widely used method, although the time required for isolation is one of the main obstacles that the clinical mycologist faces today, since it needs a period of 15 to 21 days to obtain results, in addition to requiring a trained staff

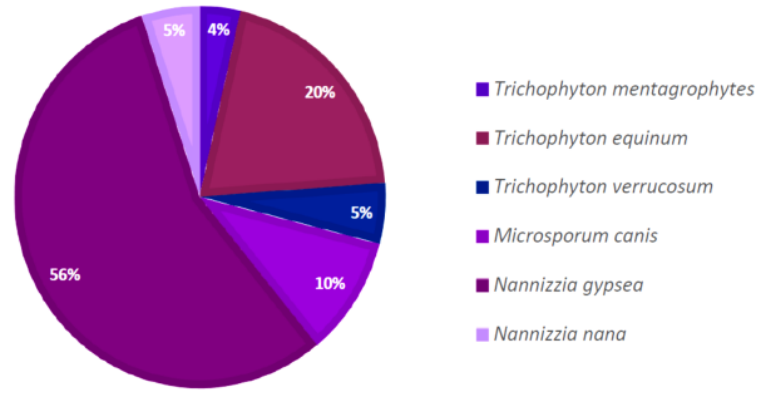

Fig. 1: The graph exposes the percentage of isolated species common in horses, according to previous research realized in Mexico City.

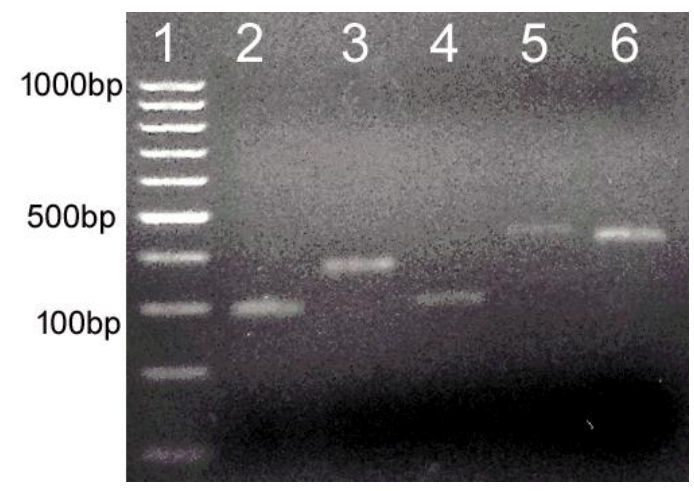

Fig. 2: PCR amplifications of the reference strain and each isolate. Lane 1: 100 bp molecular weight marker; lane 2: $M$. canis 297 bp (N2); lane 3: N. gypsea 373 bp (K38); lane 4: T mentagrophytes $331 \mathrm{bp}(\mathrm{H} 2)$; lane 5: T. equinum 442 bp (CBS 292.81); lane 6: T. verrucosum 426bp (Z29).

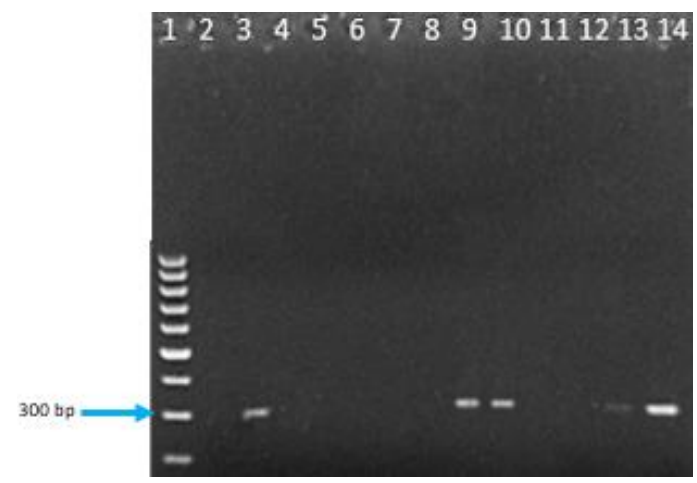

Fig. 3: Figure shows the sensitivity of $M$. canis, in the isolation there were only 2 positive simples, in the PCR two more positive samples are observed. PCR $M$. canis: Lane 1: 100 bp DNA Ladder, lane 2: negative control; lane 3: positive control $M$. canis, lane 4: H2, lane 5: Poblano, lane 6: E37, lane 7: L17, lane 8: A69, Lane 9: Keiser, lane 10: F4, Lane 11: K8, lane 12: J20, lane 12 J20, lane 13: linaje, Lane 14: C6. 
Table 2: The results demonstrated in general that the PCR test had a specificity $82.2 \%$ and a sensibility $62 \%$, compared to the isolated test

\begin{tabular}{ll}
\hline Statistic & Value \\
\hline Sensitivity & 0.789 \\
Specificity & 0.821 \\
False positive rate & 0.179 \\
False negative rate & 0.211 \\
Relative risk & 3.214 \\
\hline
\end{tabular}

that can carry out a proper identification of the dermatophytes and provide an accurate result (Guarro 2012; Cafarchia et al. 2013c). Due to the long time needed to obtain an accurate diagnosis, most veterinarians do not send samples to the mycological diagnostic laboratory and prefer to administer the treatment directly.

With the advent of molecular biology, clinical mycology currently has a wide range of molecular techniques, which are useful for determining the causative agent at various taxonomic levels. (Mohtady et al. 2020; Touhali et al. 2020)

Hoog and Gräser described several genes that have been used in different studies of phylogenetic analysis and in the diagnosis of dermatophytes, including the ITS region and the $\beta$-tubulin (BT2) genes, the translation of the elongation factor $1 \alpha$ (TEF- $1 \alpha$ ), calmodulin, 60S, LSU, topoisomerase II (TOP II) and chitin synthetase 1 (CHS-1) (Guarro 2012; De Hoog et al. 2016).

The most commonly used regions for the diagnosis of dermatophytes correspond to the ITS region and the translation factor of the $1 \alpha$ elongation (TEF-1 $\alpha$ ) for the Trichophyton genus; while for Microsporum and Nannizzia only the ITS region is used, since in these regions significant differences can be found for each species, according to De Hoog et al. 2016.

In veterinary medicine there are only two studies conducted in equines. The first one corresponds to the study performed by El-yazeed et al. (2013), who developed a PCR test using the CHS-1 gene; their results showed that the PCR test had a sensitivity of $73.3 \%$, which is not very far from the results obtained in our study. Chung et al. (2010), who also used the CHS-1 gene, conducted the second study; these researchers reported that both conventional and molecular tests showed a sensitivity of 66.66\% (Shehata et al. 2008; Chung et al. 2010; Refai et al. 2013). Given the above, we still need further studies to obtain an adequate sensitivity for a PCR test, if it is intended for diagnostic use. We Achievements successfully standardize a PCR test for the diagnosis of the most common dermatophytes in equidae.

\section{Conclusion}

Conventional mycological diagnosis remains the most widely used method, although the time required for isolation is one of the main obstacles that the clinical mycologist faces today, since it needs a period of 15 to 21 days to obtain results, the most commonly used regions for the diagnosis of dermatophytes correspond to the ITS region and the TEF- $1 \alpha$. With the 22 isolates previously obtained, sensitivity and specificity tests were performed on the primers; Nevertheless; the expected results were not obtained in terms of sensitivity in the specific case of Trichophyton mentagrophytes, so they will have to modify the amounts of reagent that are used or design new initiators, to take the test to the next phase, which would be with DNA obtained from suspicious samples of hair and scales. For the rest of the species We achieve successfully standardize a PCR test for the diagnosis of the most common dermatophytes in equidae.

\section{Author's Contribution}

All authors participated in completing that work and approved the manuscript.

\section{REFERENCES}

Abd-Elmegeed M, El-Mekkawi MF, El-Diasty EM and Fawzi EM, 2020. Dermatophytosis among ruminants in Egypt: The infection rate, identification and comparison between microscopic, cultural and molecular methods. Zagazig Veterinary Journal 48: 116-127. https://doi.org/10.21608/ zvjz.2019.16779.1081.

Acha PN and Szyfres B, 2001. Zoonosis y enfermedades transmissible comunes al hombre y a los animales Vol. 1 Bacteriosis y micosis. 3rd Ed. Organización Panamericana de la Salud, Washington DC, USA, pp: 354-361.

Begum J, Mir NA, Lingaraju MC, Buyamayum B and Dev K, 2020. Recent advances in the diagnosis of dermatophytosis. Journal of Basic Microbiology 60: 293303. https://doi.org/10.1002/jobm.201900675.

Bonifaz AT, 2010. Micología Médica Básica, 3rd Ed. McGrawHill Interamericana, México, pp: 93.

Cafarchia C, Figuerado LA, Otranto D, 2013a. Fungal diseases of horses. Veterinary Microbiology 167: 215-34. https://doi.org/10.1016/j.vetmic.2013.01.015.

Cafarchia, C, Gasser RB, Figueredo LA, Weigl S, Danesi P, Capelli G and Otranto D, 2013b. An improved molecular diagnostic assay for canine and feline dermatophytosis. Medical Mycology 51: 136-143. https://doi.org/10.3109/ 13693786.2012.691995.

Cafarchia, C, Iatta R, Latrofa MS, Gräser Y and Otranto D, 2013c. Molecular epidemiology, phylogeny and evolution of dermatophytes. Infection, Genetics and Evolution, 20: 336351. https://doi.org/10.1016/j.meegid.2013.09.005.

Chung T H, Park GB, Pim CY, Park HM, Choi GC, Youn HY and Hwang Y, 2010. A rapid molecular method for diagnosing epidemic dermatophytosis in a racehorse facility. Equine Veterinary Journal 42: 73-78. https://doi.org/10.2746/ 042516409X475337.

De Hoog GS, Dukik K, Monod M, Packeu A, Stubbe D, Hendrickx M and Rezaei-Matehkolaei A, 2017. Toward a novel multilocus phylogenetic taxonomy for the dermatophytes. Mycopathologia 182: 5-31. https://doi.org/ 10.1007/s11046-016-0073-9.

Dukik K, De Hoog GS, Stielow J B, Freeke J, van den Ende BG, Vicente VA and Ahmed SA, 2020. Molecular and phenotypic characterization of Nannizzia (Arthrodermataceae). Mycopathologia 185: 9-35. https://doi.org/10.1007/s11046-019-00336-9.

Garg J, Tilak R, Garg A, Prakash P, Gulati AK and Nath G, 2009. Rapid detection of dermatophytes from skin and hair. BMC Research Notes 2: 60. https://doi.org/10.1186/1756-0500-2$\underline{60 .}$

Gräser Y, El Fari M, Vilgalys R, Kuijpers AFA, De Hoog GS, Presber W and Tietz HJ, 1999. Phylogeny and taxonomy of the family Arthrodermataceae (dermatophytes) using sequence analysis of the ribosomal ITS region. Medical Mycology 37: 105-114. https://doi.org/10.1080/0268121 9980000171.

Grob H, Wyss F, Wenker C, Uhrlaß S, Krüger C, Mayser P, Nenoff P 2018. Trichophyton mentagrophytes-from snow leopard to man: A molecular approach for uncovering the 
chain of infection. Der Hautarzt; Zeitschrift fur Dermatologie, Venerologie, und verwandte Gebiete 69: 1021-1032. https://doi.org/10.1007/s00105-018-4234-2

Guarro J, 2012. Taxonomía y biología de los hongos causantes de infección en humanos. Enfermedades Infecciosas y Microbiología Clínica 30: 33-39. https://doi.org/10.1016/ j.eimc.2011.09.006

El-Yazeed HA, Effat M. Abdalla K, Bakry M, Alarousy R and Farahat E, 2013. Application of molecular techniques for rapid diagnosis of dermatophytes infection in horses. Global Vetereinary 10: 310-313. http://www.idosi.org/gv/gv10(3) 13/11.pdf

Hamad MH, Mohamed ME, El-Blkemy FA, Abouzeid NZ and Tartor YH, 2019. Clinical And Laboratory Studies On Equine Dermatophytosis. Benha Veterinary Medical Journal 36: 23-31. https://dx.doi.org/10.21608/bvmj.2019. 98467

Kandemir H, Dukik K, Hagen F, Ilkit M, Graeser Y and de Hoog GS, 2020. Polyphasic discrimination of Trichophyton tonsurans and T. equinum from humans and horses. Mycopathologia 185: 113-122. https://doi.org/ 10.1007/s11046-019-00344-9

Kong F, Tong Z, Chen X, Sorrell T, Wang B, Wu Q, Ellis D and Chen S, 2008. Rapid identification and differentiation of Trichophyton species, based on sequence polymorphisms of the ribosomal internal transcribed spacer regions, by rollingcircle amplification. Journal of Clinical Microbiology 46: 1192-1199. https://doi.org/10.1128/JCM.02235-07

Mendoza L, 2002. Manual de Procedimientos. Course of Molecular Mycology, Medical Technology Program. Michigan State Michigan State University.

Mirhendi H, Makimura K, de Hoog GS, Rezaei-Matehkolaei A, Najafzadeh MJ, Umeda Y and Ahmadi B, 2015. Translation elongation factor 1- $\alpha$ gene as a potential taxonomic and identification marker in dermatophytes. Medical Mycology 53: 215-224. https://doi.org/10.1093/mmy/ myu088

Mohtady H, Nassar A, Elbadawy NE and Abdelhafiz M, 2020. The role of PCR in the diagnosis of dermatophytes in onychomycosis. The International Arabic Journal of Antimicrobial Agents 9: 3. http://dx.doi.org/10.3823/838

Parmar BC, Nayak JB, Brahmbhatt MN, Chaudhary JH, Patel SA and Gida HK, 2018. Prevalence of Dermatophytosis in Animal and Human Population with Special Reference to Its Zoonotic Significance. International Journal of Pure and Applied. Bioscience 6: 687-691. http://dx.doi.org/10.18782/ 2320-7051.6991

Paryuni AD, Indarjulianto S and Widyarini S, 2020. Dermatophytosis in companion animals: A review. Veterinary World 13: 1174. https://doi.org/ 10.14202/vetworld.2020.1174-1181

Pascoe RR, Knottenbelt CD, McGarry WJ, 2009, Principles \& Practice of Equine Dermatology. $2^{\circ}$ Ed. Saunders, London, UK; pp: 167-175.

Pchelin IM, Zlatogursky VV, Rudneva MV, Chilina GA, RezaeiMatehkolaei A, Lavnikevich DM, Vasilyeva NV and Taraskina AE, 2016. Reconstruction of phylogenetic relationships in dermatomycete genus Trichophyton Malmsten 1848 based on ribosomal internal transcribed spacer region, partial $28 \mathrm{~S}$ rRNA and beta-tubulin genes sequences. Mycoses 59: 566-575. https://doi.org/10.1111/ myc. 12505

Psifidi A, Dovas CI, Bramis G, Lazou T, Russel CL, Arsenos G and Banos G, 2015. Comparison of eleven methods for genomic DNA extraction suitable for large-scale wholegenome genotyping and long-term DNA banking using blood samples. PloS One 30: 10. https://doi.org/10.1371/ journal.pone. 0115960

Rakeman JL, Bui U, LaFe K, Chen YC, Honeycutt RJ and Cookson BT, 2005. Multilocus DNA sequence comparisons rapidly identify pathogenic molds. Journal of Clinical Microbiology 43: 3324-3333. $\quad$ https://doi.org/10.1128/ JCM.43.7.3324-3333.2005

Refai M, Heidy AE and Mahmoud E, 2013. Monograph on dermatophytes. Department of Microbiology, Faculty of Veterinary Medicine, Cairo University. https://scholar.cu. edu.eg/sites/default/files/hanem/files/monograph_on_derma tophytes.pdf

Salem M, Al-Bulushi S, Eljalii I, Fadlelmula A and Housawi F, 2018. A Regional Study on dermatophytes infection in arabian dromedary camels (Camelus dromedaries) in $\mathrm{Al}-$ Hassa Governorate in the Eastern Province of Saudi Arabia. Current Journal of Applied Science and Technology Volume missing?? 1-8. https://doi.org/10.9734/CJAST/ $\underline{2018 / 41288}$

Silva MB, Conceição LG, Bevilacqua PD, de Campos SG, Jimenez AKA and de Souza MV, 2018. Prevalence and factors associated with dermatophytes in equine: A study of hospital demand. Advances in Biotechnology and Microbiology 9: 103-104. https://doi.org/10.19080/ AIBM.2018. 09.555774

Shehata AS, Mukherjee PK, Aboulatta HN, El Akhras AI, Abbadi SH and Ghannoum MA, 2008. Single-step PCR using (GACA) 4 primer: utility for rapid identification of dermatophyte species and strains. Journal of Clinical Microbiology 46: 2641-2645. https://doi.org/10.1128/JCM. 00697-08

Summerbell RC, Haugland RA, Li A and Gupta AK, 1999. rRNA gene internal transcribed spacer 1 and 2 sequences of asexual, anthropophilic dermatophytes related to Trichophyton rubrum. Journal of Clinical Microbiology 37: 4005-4011. https://doi.org/10.1128/JCM.37.12.4005-4011.1999

ST-Germain G andSummerbell R. 2011, Identifying Fungi, a clinical laboratory handbook, $2^{\circ}$ edit., Star publishing company inc., Korea, page: 172, 248, 254.

Touhali IS and Mohammed MI, 2020. Isolation And Molecular Detection of dermatophytes from horses in the Governorate Of Wasit, IRAQ. Annals of Tropical Medicine and Health 23: 147-154. http://doi.org/10.36295/ASRO. $\underline{2020.23517}$

Weitzman I and Summerbell RC, 1995, The Dermatophytes. Clinical Microbiology Reviews 240-259. https://doi.org/10.1128/CMR.8.2.240-259.1995 